\section{Factors influencing diarrheal prevalence among children under five years in Mathare Informal Settlement, Nairobi, Kenya}

\author{
Djounfoune A. Guillaume, Osero O.S. \\ Justus, Kabiru W. Ephantus \\ Department of Community Health and \\ Epidemiology, Kenyatta University, \\ Nairobi, Kenya
}

\begin{abstract}
Globally, diarrhoea is the second major cause of death among children under five years. The aim of the study was to establish factors influencing diarrhoeal prevalence among children under five years in Mathare Informal Settlement. Cross-sectional survey was used. Data was collected from $1^{\text {st }}$ July to $1^{\text {st }}$ August 2019 among primary caregivers (PCGs) of children under five years in Mathare Informal Settlement, in Nairobi, Kenya. This urban informal settlement in Kenya was purposively sampled. Simple random sampling was used to select the households and the respondents. $\mathrm{P}<0.05$ was considered as statistically significant. A total of 324 primary caregivers selected from 324 households were included in the study. Fifty six point seventeen percent of same study, the exact prevalence of diarrhoea among children in Mathare Informal Settlement was not mentioned, Primary Caregivers (PCGs) reported that their children contract diarrhoea at least once every two weeks. ${ }^{3}$ PCGs play an important role in the management process of diarrhoea as they are the first person directly related to the child. There are limited studies on the factors influencing diarrhoeal prevalence among children under five years in Mathare Informal Settlement. As diarrhoea is mostly managed at home by PCGs, we need to establish factors influencing management practices in order to come up with effective health promotion programmes. The study therefore aims at establishing factors influencing diarrhoeal prevalence among children under five years in Mathare Informal Settlement, in Nairobi, Kenya.
\end{abstract} the respondents were aged 25-31 years old. Prevalence of diarrhoea among children was $18.7 \%$. Sex, relationship of the primary caregivers, number of people and children in the households were found to be statistically significant with diarrhoea prevalence with $\mathrm{p}=0.008, \mathrm{p}<0.001, \mathrm{p}<0.001, \mathrm{p}<0.001$ respectively. One hundred and seventy one $(52.78 \%)$ primary caregivers had no formal education. primary caregivers disposed of the child's faeces in garbage in $38.89 \%$ of the cases. Education level of the primary caregivers, renting, presence of flies, faeces, and open garbage near or within the compound were found to be associated with diarrhoea prevalence with $\mathrm{p}<0.001$, $\mathrm{p}=0.024, \mathrm{p}<0.001, \mathrm{p}<0.001$ respectively. Several factors were found to be associated with diarrhoeal prevalence among children under five years.

\section{Introduction}

Globally, the burden of diarrhoeal infections among children under five years remains high. According to World Health Organization (WHO), diarrhoea is one of the major causes of death among children under five years worldwide and it is classified as the second main cause of death. Every year, there is an estimated number of dren under five years. WHO estimates that every year, around 525,000 children under five years die due to diarrhoeal disease. ${ }^{1}$ In Kenya, during the year 2018, 1,499,146 cases of diarrhoea were reported among children under five years. Among the cases of diarrhoea in 2018 in Kenya, Nairobi accounted for 136,028 cases. $^{2}$

A study showed that in $2017,25.6 \%$ of children living in Nairobi Informal Settlement had diarrhoea. Although in the

\section{Materials and Methods}

\section{Study area}

The study took place in Mathare Informal Settlement, located within Nairobi, Kenya. Mathare is exactly located at latitude $1^{\circ} 15^{\prime} 42.88^{\prime} \mathrm{S}$ and longitude $36^{\circ} 51$ '30.53'E. The study focused on three villages of Mathare: Gitathuru, 4A, and 4B.

\section{Study design}

Due to the variables, the lower cost of the study design, as well as the fact that it can be applied to many people within a short period of time, cross sectional survey was utilized. It was a community based study.

\section{Study variables}

The following were considered independent variables: age group of the PCG, sex of the PCG, relationship of the PCG, number of household $(\mathrm{HH})$ residents, number of children under five years in a $\mathrm{HH}$, education level of the PCG, occupation of the PCG, monthly income, rent, type of 1.7 billion cases of diarrhoea amongst chil-
Correspondence: Djounfoune Arnaud Guillaume, Kenyatta University, P.O Box: 43844-00100 Nairobi, Kenya.

Tel.: +254.740233891

E-mail: arnaudjounfoune@gmail.com

Key words: Diarrhoea; caregivers; children.

Contributions: DAG: Conception, data collection, data analysis, interpretation of results; OOSJ: Conception, proofreading, final approval of the version to be published; KWE: Conception, proofreading, final approval of the version to be published.

Conflict of interest: The authors declare no conflict of interest.

Ethics approval and consent to participate: Ethical approval was obtained from Kenyatta University Ethics Review Committee under the approval number PKU/1001/11051. Authority was sought by the National Commission for Science, Technology, and Innovation under the permit NACOSTI/P/ 19/57924/31181. Clearance to conduct the research was obtained from the County Director of Health, the County Commissioner, and the County Director of Education.

Consent for publication: Informed consent was obtained from the participants.

Availability of data and materials: All data and materials are available within the text.

Received for publication: 6 December 2019 .

Revision received: 15 July 2020.

Accepted for publication: 15 July 2020.

This work is licensed under a Creative Commons Attribution NonCommercial 4.0 License (CC BY-NC 4.0).

CC Copyright: the Author(s),2020

Licensee PAGEPress, Italy

Journal of Public Health in Africa 2020; 11:1312 doi:10.4081/jphia.2020.1312

latrine used, presence of flies near/within the $\mathrm{HH}$, presence of open garbage, presence of faeces near/within the $\mathrm{HH}$, hand washing practices after using the toilet, hand washing practices after disposing of the child's faeces and the reason, place of defecation of the child, age when the child starts using latrine, disposal of the child's faeces, immunization practices. The following were considered as dependent variables: diarrhoea prevalence among children under five years during the two last weeks preceding the data collection.

\section{Study population}

The study targeted PCGs of children 
under five years living in the selected villages of Mathare Informal Settlement. A PCG is the individual directly responsible, particularly for a child.

\section{Inclusion criteria}

Participants were eligible for the study if they met the following inclusion criteria: PCG of children under-five years; Only children under the responsibility of the selected PCG; One PCG per selected households.

\section{Exclusion criteria}

The study excluded PCG of children under-five years who were unwilling to participate in the study.

\section{Sampling techniques}

Mathare Informal Settlement was purposively sampled because of the frequency of diarrhoea reported by PCGs. Simple random sampling was applied to select the three villages (Gitathuru, 4A, and 4B), the households, and the respondents.

\section{Sample size determination}

The formula by Fischer et al. ${ }^{4}$ was used:

$$
n=\frac{z^{2} p q}{d^{2}}
$$

with,

$\mathrm{n}=$ desired sample size

$\mathrm{z}=$ the $95 \%$ of confidence interval which is 1.96

$\mathrm{p}=$ the proportion of people in the target population estimated to have the characteristic that is measured. $\mathrm{p}=25.6 \%=0.256 .^{3}$

$\mathrm{q}=1-\mathrm{p}=0.744$

$\mathrm{d}=$ the level of statistical significance which is 0.05

$$
n=\frac{1.96^{2} * 0.256 *(1-0.256)}{0.05^{2}}
$$

$\mathrm{n}=292.67$

$\mathrm{n}=293$

A minimum of 293 PCGs was required. The research adopted 324 as sample size. The proportionate probability was used to calculate the respondents according to the selected villages. Village 4A has 5627 households, village 4B has 1810 households, and Gitathuru has 1241 households. ${ }^{5}$ The total number of households in the selected villages is 8678 . In this study, 210 households were targeted in village A, 68 in village B and 46 in Gitathuru.

\section{Data collection techniques and data analysis}

Data was collected from $1^{\text {st }}$ July to $1^{\text {st }}$ August 2019 using interview schedule as well as observation checklist and entered into Epi-info version 7 software (CDC, Atlanta, Georgia, USA). IBM SPSS version 21 software (IBM Corp., Armonk, New York, USA) was used for analysis. Pearson Chi-square and Pearson correlation were performed. For value less than 5, Fisher's and exact test was performed. The level of confidence used is $95 \%$. $\mathrm{P}<0.05$ was considered as statistically significant.

\section{Study approvals and ethical consid- erations}

Ethical approval was obtained from Kenyatta University Ethics Review Committee under the approval number PKU/1001/11051. Authority was sought by the National Commission for Science, Technology, and Innovation under the permit NACOSTI/P/19/57924/31181. Clearance to conduct the research was obtained from the County Director of Health, the County Commissioner, and the County Director of Education. Informed consent was obtained from the participants.

\section{Results}

Demographic characteristics of primary caregivers and prevalence of diarrhoea among children under five years in the selected households

\section{Demographic characteristics of primary caregivers}

The majority of the respondents 182 (56.17\%) were aged between 25-31 years. The selected households' size ranged between 2 to 15 people. The majority of the PCGs $112(34.6 \%)$ were 4 to 5 in a household $(\mathrm{HH})$. Eighty six $(26.5 \%)$ respondents were 6 to 7 per HH. Only 1 respondent $(0.3 \%)$ was living in a HH size of 14 people. Six hundred and thirty one children under five years were living in the selected $\mathrm{HH}$ of the study. The number of children under five years per selected $\mathrm{HH}$ ranged from 1 to 7. One hundred and sixty children 160(49.4\%) were 1 per HH (Table 1).

\section{Prevalence of diarrhoea among children under five years in the selected house- holds}

Among the 631 children, 118 cases of diarrhoea were reported within the two weeks preceding the study. Therefore, that makes a prevalence of $18.7 \%$.
Demographic factors of primary caregivers and prevalence of diarrhoea among children under five years in the selected households

Sex, relationship of the PCG, number of $\mathrm{HH}$ resident, and number of children under five years in the HH were found to be statistically significant with the prevalence of diarrhoea among children under five years with $p=0.008, p<0.001, p<0.001$, and $\mathrm{p}<0.001$ respectively. Females were found to be at greater risk $(r=-0.156)$. The higher the number of $\mathrm{HH}$ resident, the greater the likelihood of diarrhea $(r=-0.320)$. This applies also to the number of children under five years per $\mathrm{HH}(\mathrm{r}=-0.505)$ (Table 2).

\section{Factors influencing diarrhoeal} prevalence among children under five years in Mathare Informal Settlement

\section{Socio economic factors}

Only 90 respondents $(27.8 \%)$ owned a house. Out of the 324 respondents, 259 $(79.9 \%)$ were earning less or equal to 10.000 Kenya shillings per month. Only 3 respondents $(0.9 \%)$ had fixed term contract. Five $(1.5 \%)$ respondents attended university (Table 2).

\section{Environmental factors}

Observation was performed. Faeces were present near or within a house in 106 $\mathrm{HH}(37.72 \%)$, garbage was present near or within the compound in $192 \mathrm{HH}(59.26 \%)$. Flies were present near or within the compound in $260 \mathrm{HH}(80.25 \%)$ (Table 2).

\section{Behavioural factors}

The research identified three categories of behavioural factors: hygiene practices, sanitation practices, and immunization practices.

All the respondents stated that they wash their hands after coming out from the latrine because the public latrine had hand washing facility and soap. However, 90 respondents $(27.78 \%)$ did not wash their hands after disposing of the child's faeces. One hundred and twenty six PCGs (38.89\%) disposed of the child's faeces in garbage. Those 126 PCGs $(38.89 \%)$ who disposed of the child's faeces in garbage and the 6 PCGs (1.85\%) whose children directly defecated in an open space, the reason was poverty. Those who disposed of the child's faeces in a latrine $150(46.3 \%)$ plus those 42 PCGs (12.96\%) whose child defecated directly in a latrine stated that they want to keep the environment clean (Table 2). The study went further to perform a cross tabulation between the factors and 
diarrhoea prevalence among children under five year in the selected households. The results showed that the level of education of the PCG, renting, presence of flies near or within the compound, presence of faeces near or within the compound, presence of open garbage near or within the compound, immunization practices, and age when children start using latrine were found to have a statistical significance with diarrhoea prevalence among children under five years with $\mathrm{p}<0.001, \mathrm{p}=0.024, \mathrm{p}<0.001, \mathrm{p}<0.001$, $\mathrm{p}<0.001, \mathrm{p}<0.001$ respectively. Non immunization was associated with high prevalence $(r=-0.172)$. Low level of education, not owning a house, presence of flies, presence of open garbage and presence of faeces were associated with high prevalence of diarrhoea among children under five years (Table 2).

\section{Discussion}

The prevalence of diarrhoea among children under five years in the selected households was $18.7 \%$. This finding on prevalence of diarrhoea among children under five years is similar to the study con- ducted in Ethiopia where the two weeks prevalence of diarrhoea among children under five years was $22.5 \% .{ }^{6}$ Similar results were obtained in a study done in Turkana County in Kenya where the two weeks prevalence was $16.5 \% .^{7}$ Diarrhoea among children under five years was predominant among young PCGs. This demonstrates that PCGs were mature enough to answer the questions. This finding corroborates with a study conducted in Nepal, which showed that majority of PCGs whose child experienced diarrhoea were young. This can be explained by lack of prior experiences. ${ }^{8}$ The study established that sex female of the PCG was associated with the occurrence of diarrhoea among children under five years. This can be explained by the fact that the majority of the PCGs $(307,94.8 \%$ ) were female. The prevalence of diarrhoea was high in households with high number of people as well as households with high number of children under five years. This study demonstrates that crowded housing condition is a predicator of diarrhoea occurrence among children under five years. Other researches also showed that the high number of children under five years in a household was a predictor of diarrhoea among children. 6,9 This could be attributed to the PCG failure to look after many kids. The study also found that risk of diarrhoea occurrence among children was low if the PCG was the biological parent (mother or father). This could be explained by the fact that a biological parent cares more about the health of his/her child.

PCGs with no formal education recorded high prevalence of diarrhoea among children under five years. Low education level of the PCG was associated with the occurrence of diarrhoea among children under five years. Similar results were obtained by a study conducted in Northeast Ethiopia. Children of the PCGs who were selfemployed, casual workers, had fixed termed, and housewives experienced diarrhoea but the difference was not significant. This result differs from the study conducted in Northeast Ethiopia where occupation of the PCG was associated with diarrhoea prevalence among children under five years. This could be explained by the study area where the majority of PCGs in Northeast Ethiopia are housewives. ${ }^{10}$ PCGs who were renting recorded high prevalence of diarrhoea among children under five years. Owning a house was associated with

Table 1. Demographic characteristics of primary caregivers and prevalence of diarrhoea among children under five years in the selected households, Mathare Informal Settlement, Nairobi, Kenya, July-August 2019.

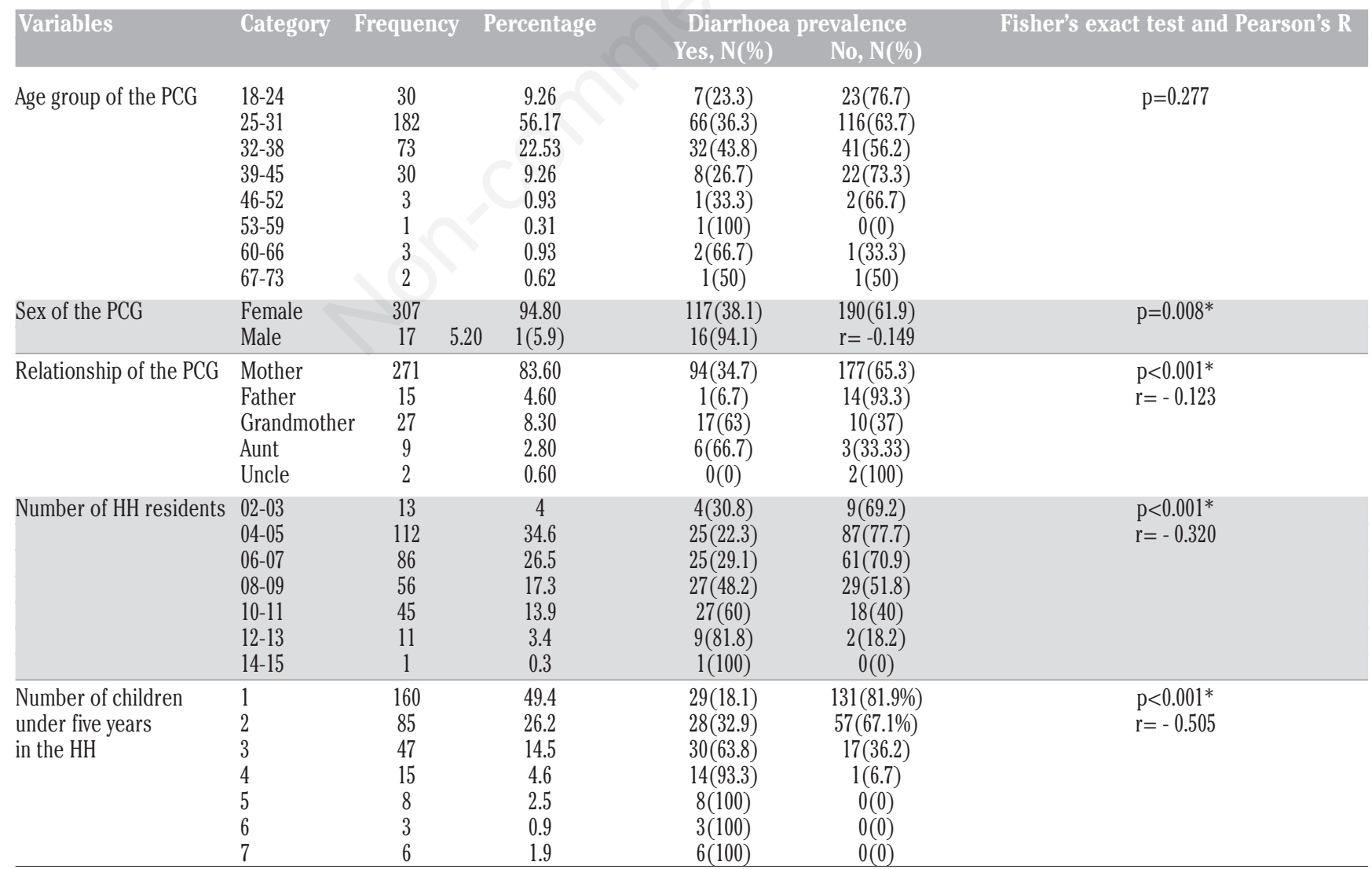

HH=Household, N=Frequency, PCG=Primary caregiver, p=P-value, r=Pearson's R, *statistically significant. 
low risk of diarrhoea compare to renting a house. The government made an effort in building public latrines in Mathare and put it at an affordable price. All the respondents were using public latrines. However, despite the price, a study done in Mathare found that people were still using flying toilet in Mathare. ${ }^{11}$ The difference could be explained by the study period. Since 2014 , efforts were made by the authorities to change behaviour. ${ }^{12}$ Despite the efforts made to change behaviour, faeces were found around many compounds. Although the price for using a public latrine is low, some families have high number of children and they can't afford to pay for every child. Therefore, either they throw the faeces in the garbage or the child defecates on an open space. Presence of flies, presence of open garbage and presence of faeces near or around the compound were found to be associated with occurrence of diarrhoea among children. These findings are similar to the finding of a study conducted in Ethiopia where open garbage was an independent risk factor for developing diarrhoeal diseases. ${ }^{6}$ The easy reason could be that the unsuitable disposal of waste is a breeding ground for animals that can carry diarrhoeal pathogens from garbage or fae-

Table 2. Factors influencing diarrhoea prevalence among children under five years in Mathare Informal Settlement, Nairobi, Kenya, July-August 2019.

\begin{tabular}{|c|c|c|c|c|c|c|}
\hline \multirow[t]{2}{*}{ Variables } & \multirow[t]{2}{*}{ Category } & \multicolumn{2}{|c|}{ Total } & \multicolumn{2}{|c|}{ Diarrhoea Prevalence } & \multirow{2}{*}{$\begin{array}{l}\chi^{2} / \text { Fisher's exact test } \\
\text { and Pearson's } \mathbf{R}\end{array}$} \\
\hline & & $\mathbf{N}$ & $\%$ & Yes N(\%) & No $N(\%)$ & \\
\hline \multicolumn{7}{|c|}{ Socio economic factors } \\
\hline Education level of the PCG & $\begin{array}{l}\text { No formal education } \\
\text { Primary school } \\
\text { Secondary school } \\
\text { University }\end{array}$ & $\begin{array}{c}171 \\
78 \\
70 \\
5\end{array}$ & $\begin{array}{c}52.8 \\
24.1 \\
21.6 \\
1.5\end{array}$ & $\begin{array}{l}101(59.1) \\
11(14.1) \\
6(8.6) \\
0(0)\end{array}$ & $\begin{array}{c}70(40.9) \\
67(85.9) \\
64(91.4) \\
5(100)\end{array}$ & $\begin{array}{l}\mathrm{p}<0.001^{*} \\
\mathrm{r}=0.465\end{array}$ \\
\hline Occupation of the PCG & $\begin{array}{l}\text { Self-employed } \\
\text { Casual worker } \\
\text { Fixed term } \\
\text { Housewife }\end{array}$ & $\begin{array}{l}140 \\
85 \\
3 \\
96\end{array}$ & $\begin{array}{c}43.2 \\
26.2 \\
9 \\
29.6\end{array}$ & $\begin{array}{c}43(30.7) \\
31(36.5) \\
1(33.3) \\
43(44.8)\end{array}$ & $\begin{array}{l}97(69.3) \\
54(63.5) \\
2(66.7) \\
53(55.2)\end{array}$ & $\mathrm{p}=0.182$ \\
\hline Monthly income (Kenya shillings) & $\begin{array}{l}\leq 10000 \\
>10000\end{array}$ & $\begin{array}{l}259 \\
65\end{array}$ & $\begin{array}{l}79.9 \\
20.1\end{array}$ & $\begin{array}{l}99(38.2) \\
19(29.2)\end{array}$ & $\begin{array}{l}160(61.8) \\
46(70.8)\end{array}$ & $\chi^{2}=1.815, \mathrm{df}=1, \mathrm{p}=0.178$ \\
\hline Rent & $\begin{array}{l}\text { Renting } \\
\text { Not renting }\end{array}$ & $\begin{array}{c}234 \\
90\end{array}$ & $\begin{array}{l}72.2 \\
27.8\end{array}$ & $\begin{array}{l}94(40.2) \\
24(26.7)\end{array}$ & $\begin{array}{l}140(59.8) \\
66(73.3)\end{array}$ & $\begin{array}{c}\chi^{2}=5.119, \mathrm{df}=1, \mathrm{p}=0.024^{*} \\
\mathrm{r}=0.126\end{array}$ \\
\hline Type of latrine used & $\begin{array}{l}\text { Public latrine } \\
\text { Family latrine }\end{array}$ & $\begin{array}{c}324 \\
0\end{array}$ & $\begin{array}{c}100 \\
0\end{array}$ & $\begin{array}{c}118(36.4) \\
0(0)\end{array}$ & $\begin{array}{c}206(63.6) \\
0(0 \%)\end{array}$ & $\mathrm{NA}$ \\
\hline \multicolumn{7}{|c|}{ Environmental factors } \\
\hline $\begin{array}{l}\text { Presence of flies near/ } \\
\text { within the } \mathrm{HH}\end{array}$ & $\begin{array}{l}\text { Yes } \\
\text { No }\end{array}$ & $\begin{array}{l}260 \\
64\end{array}$ & $\begin{array}{l}80.25 \\
19.75\end{array}$ & $\begin{array}{l}111(42.7) \\
7(10.9)\end{array}$ & $\begin{array}{l}149(57.3) \\
57(89.1)\end{array}$ & $\begin{array}{c}\chi^{2}=22.365, \mathrm{df}=1, \mathrm{p}<0.001^{*} \\
\mathrm{r}=0.263\end{array}$ \\
\hline Presence of open garbage & $\begin{array}{l}\text { Yes } \\
\text { No }\end{array}$ & $\begin{array}{l}192 \\
132\end{array}$ & $\begin{array}{l}59.26 \\
40.74\end{array}$ & $\begin{array}{l}86(44.8) \\
32(24.2)\end{array}$ & $\begin{array}{l}106(55.2) \\
100(75.8)\end{array}$ & $\begin{array}{c}\chi^{2}=14.265, \mathrm{df}=1, \mathrm{p}<0.001^{*} \\
\mathrm{r}=0.210\end{array}$ \\
\hline $\begin{array}{l}\text { Presence of faeces near/ } \\
\text { within the } \mathrm{HH}\end{array}$ & $\begin{array}{l}\text { Yes } \\
\text { No }\end{array}$ & $\begin{array}{l}106 \\
218\end{array}$ & $\begin{array}{l}37.72 \\
62.28\end{array}$ & $\begin{array}{l}55(51.9) \\
63(28.9)\end{array}$ & $\begin{array}{l}51(48.1) \\
155(71.1)\end{array}$ & $\begin{array}{c}\chi^{2}=16.276, \mathrm{df}=1, \mathrm{p}<0.001^{*} \\
\mathrm{r}=0.224\end{array}$ \\
\hline \multicolumn{7}{|c|}{ Behavioural factors Hygiene practices } \\
\hline $\begin{array}{l}\text { Hand washing practices after } \\
\text { using the toilet }\end{array}$ & $\begin{array}{l}\text { Washed their hands } \\
\text { Did not wash their hands }\end{array}$ & $\begin{array}{c}324 \\
0\end{array}$ & $\begin{array}{c}100 \\
0\end{array}$ & $\begin{array}{l}118(36.4) \\
0(0)\end{array}$ & $\begin{array}{l}206(63.6) \\
0(0)\end{array}$ & NA \\
\hline $\begin{array}{l}\text { Hand washing practices after } \\
\text { disposing of the child's faeces } \\
\text { and the reason }\end{array}$ & $\begin{array}{l}\text { Washed their hands } \\
\text { Didn't Wash their hands } \\
\text { Washed their hands sometimes }\end{array}$ & $\begin{array}{l}218 \\
90 \\
16\end{array}$ & $\begin{array}{r}67.28 \\
27.78 \\
4.94 \\
\end{array}$ & $\begin{array}{c}74(33.9) \\
35(38.9) \\
9(56.3)\end{array}$ & $\begin{array}{l}144(66.1) \\
55(61.1) \\
7(43.8)\end{array}$ & $\chi^{2}=3.531, d f=2, p=0.171$ \\
\hline \multicolumn{7}{|c|}{$\begin{array}{l}\text { Sanitation practices } \\
\end{array}$} \\
\hline Place of defecation of the child & $\begin{array}{l}\text { Potty } \\
\text { Latrine } \\
\text { Diapers } \\
\text { In an open space }\end{array}$ & $\begin{array}{c}155 \\
42 \\
121 \\
6\end{array}$ & $\begin{array}{c}47.84 \\
12.96 \\
37.35 \\
1.85\end{array}$ & $\begin{array}{l}56(36.1) \\
9(21.4) \\
49(40.5) \\
4(66.7)\end{array}$ & $\begin{array}{l}99(63.9) \\
33(78.6) \\
72(59.5) \\
2(33.3)\end{array}$ & $\mathrm{p}=0.055$ \\
\hline $\begin{array}{l}\text { Age when the child starts using } \\
\text { latrine (month) }\end{array}$ & $\begin{array}{l}24 \\
36 \\
48 \\
59\end{array}$ & $\begin{array}{l}120 \\
136 \\
63 \\
5\end{array}$ & $\begin{array}{l}37.04 \\
41.98 \\
19.44 \\
1.54\end{array}$ & $\begin{array}{c}34(28.3) \\
53(39) \\
30(47.6) \\
1(20)\end{array}$ & $\begin{array}{c}86(71.7) \\
83(61) \\
33(52.4) \\
4(80)\end{array}$ & $\begin{array}{l}\mathrm{p}=0.047^{*} \\
\mathrm{r}=-0.126\end{array}$ \\
\hline Disposal of the child stool & $\begin{array}{l}\text { Latrine } \\
\text { Garbage } \\
\text { Other }\end{array}$ & $\begin{array}{l}150 \\
126 \\
48\end{array}$ & $\begin{array}{l}46.91 \\
38.89 \\
14.20\end{array}$ & $\begin{array}{l}51(33.6) \\
54(42.9) \\
13(28.3)\end{array}$ & $\begin{array}{l}101(66.4) \\
72(57.1) \\
33(71.7)\end{array}$ & $\chi^{2}=4.117, \mathrm{df}=2, \mathrm{p}=0.128$ \\
\hline \multicolumn{7}{|c|}{ Immunization practices } \\
\hline Immunization practices & $\begin{array}{l}\text { Take the child for immunization } \\
\text { Take the child sometimes for immunization } 9 \\
\text { Do not take the child for immunization }\end{array}$ & $\begin{array}{l}179 \\
95 \\
50\end{array}$ & $\begin{array}{l}55.25 \\
29.32 \\
15.43\end{array}$ & $\begin{array}{l}49(27.4) \\
27(54) \\
42(51.6)\end{array}$ & $\begin{array}{l}130(72.6) \\
23(46) \\
53(48.4)\end{array}$ & $\begin{array}{c}\chi^{2}=15.489, \mathrm{df}=2, \mathrm{p}<0.001^{*} \\
r=-0.172\end{array}$ \\
\hline
\end{tabular}

$\mathrm{df}=$ Degree of freedom, $\mathrm{HH}=$ Household, $\mathrm{N}=$ Frequency, $\mathrm{NA}=$ Not applicable, $\mathrm{PCG}=$ Primary caregiver, $\chi^{2}=$ Pearson Chi-square, $r=$ Pearson's R, *Statistically significant, $\mathrm{p}=\mathrm{P}$-value. 
ces to food and water. The majority of the respondents took their child for immunization and knew the purpose of immunization, which is for disease prevention. The risk of diarrhoea among children under five years was found to be high among PCGs who did not take their child for immunization. This finding is similar with a study conducted in a rural slum in India where children who were partially immunized had higher risk of diarrhoea. ${ }^{13}$

\section{Limitations}

One of the limitations of the study is insecurity within the field of the study. This prevented the researchers from free movement. In the study field, assaults are frequent. The limitation of this study in contrast to other studies is the fact that a focus group discussion did not take place so respondents were limited to answering the questionnaires.

\section{Conclusions}

Several factors such as number of people in a household, number of children under five years in a household, relationship of the PCG, level of education, renting, presence of flies, presence of open garbage, presence of faeces, and immunization prac- tices of the child were found to be associated with diarrhoea prevalence.

\section{References}

1. WHO. Key facts scope of diarrhoeal disease. Geneva: Wold Helath Organization; 2018:1-5. Accessed 2018 Oct 14. Available from: http:/ /www.who.int/topics/diarrhoea/en/

2. The District Health Information Software. Diarrhea among under five children. Nairobi: DHIS; 2019.

3. Concern Worldwide. Nutrition survey conducted in the slums of Nairobi, Kenya. Nairobi; 2017.

4. Fischer H, Werner M, Wagenbach D, et al. Little ice age clearly recorded in northern Greenland ice cores. Geophys Res Lett 1998;25:1749-52.

5. KNBS. 2009 Kenya population and housing census. Nairobi; 2009.

6. Meningistie B, Berhane Y, Worku A. Prevalence of diarrhea and associated risk factors among children under five years of age in eastern Ethiopia: A cross-sectional study. J Prev Med 2013;3:446-53.

7. Wanjiru AM. Caregiver's knowledge, perceptions and practices on diarrheoal diseases among children under five years in Turkana County, Kenya.
Kenyatta University; 2018.

8. Ansari M, Izham M, Ibrahim M, Ravi P. Mothers' knowledge, attitude and practice regarding diarrhea and its management in Morang Nepal: an interventional study. Trop J Pharm Res 2012;11: 847-54.

9. Hillow HS. Caregivers Knowledge and Practices in Management of diarrhoea among children aged 6-59 months in Ceelafweyn District, Sanag Region, Somaliland. Kenyatta University; 2018.

10. Woldu W, Bitew BD, Gizaw Z. Socioeconomic factors associated with diarrheal diseases among under-five children of the nomadic population in northeast Ethiopia. Trop Med Health 2016;44:7-14.

11. Corburn J, Karanja I. Informal settlements and a relational view of health in Nairobi, Kenya: sanitation, gender and dignity. Health Promot Int 2014;31: 258-69.

12. County Government. Nairobi city county health sector strategic and investment plan. Nairobi; 2017.

13. Gupta A, Sarker G, Rout AJ, Mondal T, Pal R. Risk correlates of diarrhea in children under 5 years of age in slums of Bankura, west Bengal. J Glob Infect Dis 2015;7:23-9. 